\title{
Assessing Socioeconomic Opportunities of Women Selling Injera on Street at Nekemte Town, Oromia, Ethiopia
}

Tarekegn Tariku Ebissa ( $\square$ tarekegnt.04@gmail.com )

Wollega University, Accounting and Finance Department

Research

Keywords: Injera, Teff, socioeconomic opportunities, Oromia, Ethiopia

Posted Date: August 14th, 2020

DOI: https://doi.org/10.21203/rs.3.rs-57933/v1

License: (c) (1) This work is licensed under a Creative Commons Attribution 4.0 International License.

Read Full License 


\section{Abstract}

Injera is the most preferableand popular type of feeding items in Ethiopia. Injera can be prepared from various flours of cereal grains but it mostly produced using grinded flour of cereal grain called Teff (Eragrostistef (Zucc) Trotter). This study is conducted to assess the socioeconomic opportunities of women selling Injera on the street in Nekemtetown, Oromia, Ethiopia. The main aim of the study was indentifying and analyzing the social and economic opportunities of women engaged on selling Injera on the street. Primary data was collected from 50 women currently selling Injera on street at Nekemte town through structured interview questionnaire. The interview was conducted within one month at five Injera marketing locations in the town. Simple descriptive statistic was used to analyze the collected data. The findings of the study reveal the existence of both social and economic opportunities. The significant opportunities are the existence of indigenous knowledge and skill, good future employment option, availability of high domestic \& abroad market demand, existence of high interest to work in cooperatives, existence of necessary inputs in the location, availability of cheap facilities and utilities to support the engagement and existence of eager interest to continue in supplying and trading Injera. As a result, for wise utilization of the opportunities, it is recommended to empower women engaged on selling Injera by enterprising and modernizing the production, supply and trading of Injera in Nekemte town.

\section{Introduction}

\section{Background of the Study}

Injera is the most preferable and popular type of feeding items in Ethiopia. It is widely used for feeding purpose almost in all states of the country. According to (Dijkstra et al., 2008) more that $70 \%$ of Ethiopian population regularly consumes Injera for their diet purpose. Many scholars were defined Injera as thin, fermented and flat bread consumed as staple food in Ethiopia (Yimer, 2009;Alemayehuet al., 2016;Yosephet al., 2018;Ghebrehiwotet al., 2016;Addis and Fetien, 2017). Injera can be prepared from various flours of cereal grains but it mostly produced using grinded flour of cereal grain called Teff (Eragrostistef (Zucc) Trotter) (Yimer, 2009;Ghebrehiwotet al., 2016). Teff is a cereal widely cultivated by farmers and grown only in Ethiopia. The grain flour is used to produce Injeraafter long process. It takes long time and process to convert Teff into Injeraespecially in traditional ways of preparation and cooking.

Nowadays beyond feeding, Injera is becoming one source of business and earnings for those supplying it to the market. Injera is mostly prepared and used as a source of earning by low income and jobless people specially women in Nekemte town. There are many women engaged on the supply of Injera to students, individuals, households, cafes, restaurants and hotels. Women engaged on supplying and selling Injera at Nekemte town are considering the engagement as one means of temporary employment rather than a business. As a result, they are engaged on selling Injera only to earn income for the purpose of financing their day to day life, even though, the earning is not yet adequate. 
Injera is like thin bread feeding item supplied to consumers without sauce (Wot - Amharic term). It shortens the process of cooking foods for buyers especially for lunch and dinner time by simply acquiring Injera from shops or on street without its sauce. The buyers or users of Injera mostly prepare its sauce called Wot at their home. This is because it takes shorter time and requires less process to prepare its sauce than cooking Injera.

Large numbers of women are currently engaged on supplying and trading Injera on street in Nekemte town. However, they have been received less attention from scholars and the government. Lack of adequate research conducted in this area from business perspective is its implication. The study conducted to investigate and analyze the socioeconomic opportunities of women marketing Injera on the street in Nekemte town. This assessment is very important to open the door for further study and filling the existing literature gap.

\section{Statement Of The Problem}

It is truthful to say most persons in Ethiopia feed Injera at least twice per day - during lunch and dinner time. The demand for Injera is very high in Ethiopia particularly in Nekemtetown. Here women are playing the main role in satisfying the existing strong demand for Injera by producing and supplying it on street.

On the other hand, women are currently using the indigenous skill and knowledge as well as the existence of high demand as an opportunity to create their own job by selling Injera on the street.Even though, the engagement has good future opportunities, most Injera supplier women are not considering the engagement as their future career rather than for short time relief and looking for other job option than improving it.

Regarding to previous empirical studies, many scholars have been focused on investigating the scientific specification and characteristics of Injera than its business aspects and socioeconomic opportunities for people supplyingInjera as a product. (Yimer, 2009) focused on the mineral content and sensory properties of Injera made from various cereal flours and (Alemayehuet al., 2016) studied Injerafood formulation prepared from Taro and Teff flours. Furthermore, the effect of mechanical kneading and absit preparation on teffInjera qualitywas investigated by (Yosephet al., 2018). While (Ghebrehiwotet al., 2016) examined nutritional and sensory evaluation of injera prepared from teff and schrad, (Addis and Fetien,2017)studied the effect of different cereal blends on the quality of Injera. The common aims of these researches were to explain the scientific and nutritional contents and properties of Injera made from various cereal flours. No study focuses on the business aspects of Injera product particularly the social and economic opportunities of women making and trading it as a product. Thus, this study was conducted to fill the literature gap by investigating and identifying the social and economic opportunities of women engaged on making and trading Injera on the street at Nekemte town.

\section{Research Questions}


The primary goal of this study was to indentify and analyze the social and economic opportunities of women engaged on trading Injera on the street at Nekemte town. Specifically, the study was attempting to solve the following research inquiries.

- What are the social opportunities of women engaged on selling Injera on the street at Nekemte town?

- What are the economic opportunities of women engaged on trading Injera on the street at Nekemte town?

\section{Research Objectives}

Investigating the social and economic opportunities of women selling Injera on the street at Nekemte town was the general objective of this study. Specifically, the study was conducted to:

- Explore social opportunities of women selling Injera on the street at Nekemte town.

- Investigate economic opportunities of women trading Injera on the street at Nekemte town.

\section{Significance of the study}

In addition to the aim of the study, its finding has a meaningful value to the society, government and scholars. The outcomes of this study help the government in how to take action on empowering women engaged on trading Injera and improve the society consideration about the engagement as one career and business opportunity. Finally, add new dimension of knowledge on Injera product in terms of business aspect by filling the current literature gap.

\section{Research Design And Methodology}

Exploratory descriptive research design was adopted to explore the social and economic opportunities of women engaged on Injera trading at Nekemte town. Primary data was collected through structured interview questionnaire from women currently selling Injera on the street at Nekemte town in five market locations such as Dire Tokuma, Kella, KidaneMiharet, Jiitu and Bord. These locations were sampled purposively since they cover the larger area of the town and Injera marketing place. All women selling Injera in each market location were interviewed without any discrimination at the time of data collection. The data was collected within one month from 50 women currently engaged on the trading. The collected data was analyzed using simple descriptive statistical tools such as average, percentage and charts.

\section{Analysis \& Discussion}

\section{Respondents' Demographic Characteristics}


The primary aim of this study was to identify the social and economic opportunities of women engaged on trading Injera on street at Nekemte town. In order to achieve the study objectives data was obtained from women currently engaged on the trading on Injera at Nekemte town. In general, 50 women were participated in this study. All respondents were females (50;100\%), because male does not engaged on producing and selling Injera at Nekente town. Half of the respondents' age was in between 21 to 30 years $(25 ; 50 \%)$ and least number of respondents age was between 41 to 50 years $(3 \%)$. The maximum age of respondent was 55 years while the minimum age was 14 years. The average age of women engaged on the trading Injera was 27.12 years. This implies women from teenager to older were engaged on trading Injera at Nekemte town, however, the youth takes more share. Most women were literate $(45 ; 90 \%)$ except $(5 ; 10 \%)$ of respondents which were illiterate. More than half $(47 ; 54 \%)$ of the respondents have completed 1 to $8^{\text {th }}$ grade and only $8 \%$ of the respondents have diploma. Most of women engaged on selling Injera on the street are literate. Regarding to work experience, near half $(24 ; 48 \%)$ of women have 1 to 5 years work career in the engagement, however, very few women $(2 ; 4 \%)$ have more than 15 years work experience. Others possess very few work experience on the engagement because they do not consider the engagement as future career rather for short time relief. The average work experience of the respondents was 3.60 years. These women engaged on trading Injera on the street were not only for their own survival purpose rather they were engaged on it for surviving the life their dependents too. In this case, most women $(15 ; 30 \%)$ were living with at least three dependents. Unfortunately, two women $(2 ; 4 \%)$ were serving eight dependents. The average dependent number per women was around 4 lives. This is one source of the challenges of women engaged on selling Injera on the street.

Regarding to the Injera product, Teff, maize and sorghum were most cereal flours used by women engaged on Injera trading at Nekemte town. By mixing the flours of these cereals together, they produce Injera with different quality standards. Even though we have more than two types of Teff cereals, the most frequently used types are White Teff and Red Teff. Mixing the flours of these Teff with other cereals helps to produce Injera with different quality levels. The first quality Injera is made from white Teff only and its selling price was ETB 6 per unit at the time of data collection. The second quality Injera is produced from the mix of Red Teff, Maize and Sorghum and its unit selling price was ETB 3. However, the suppliers do not hold more than one variety of Injera at a time.

\section{Major Social Opportunities}

Women trading Injera on the street at Nekemte town have good socioeconomic opportunities to use up. The first social opportunities of women engaged on trading Injera is the interest to continue in the engagement. The study result shows that $(38 ; 76 \%)$ of the women have interest to continue in the engagement as their future career if a certain improvement is made to the career.

If a certain reform is made to the career, $(40 ; 80 \%)$ of women currently engaged on trading Injera have full interest to continue with the career and $(45 ; 90 \%)$ of the women were believe it as the best way of a career. The possible required reforms to improve the current status of the engagement are giving close 
support; offering on job and entrepreneurship training; creating public awareness; electrifying the production processes; enterprising the marketing system; and creating regular customers.

The existence of indigenous knowledge and skills with the women is the second major social opportunity of the engagement. All women engaged on trading Injera on the street have good native knowledge and skills of Injera preparation. They can easily exploit the existing knowledge and skills, if they can get slight close support from stakeholders. The third possible social opportunity of women engaged on the trading is the women's interest to work in cooperative. The assessment result of the study reveals that $(43 ; 86 \%)$ of women engaged on trading Injerahave full interest to work in cooperative if the conditions aregetting suitable. Only $(7 ; 14 \%)$ of the women have no interest to work in collaboration with others, this may be due to lack of good awareness about the advantageous of cooperative.

\section{Major economic opportunities}

One of the existing economic opportunities within our town is existence of adequate and cheap utility facilities. Facilities related to utilities have major contribution to the development of one country's economy and society. As compared to other areas of the region, Nekemte town is more blessed by various utilities like electric town, water, road and transportations. The matter here is not the inadequacy of these utilities rather their wise utilization. If it is possible to cooperate and support these women engaged on trading Injera in order to modernize and enterprise the engagement, there is no big challenge with the existence of necessary utility facilities.

The second major economic opportunity of women engaged on trading Injera is the availability of necessary cereal grains for the production of Injera. Nekemte town and its surrounding areas are rich in cereal grains useful for Injera production such as Teff (White \& Red), Maize, Sorghums, etc. All necessary inputs required to produce Injera can easily be obtained from Nekemte town and its surroundings. It requires only exploiting and using them in a scientific manner.

The existence of high demand for Injera consumption in the town and abroad is the third alternative economic opportunity for Injera market. There is a big market share of Injera inside and outside of the town. This is because of the existence of high population domiciling in the town and the town is becoming a center for various sectors like universities, colleges, industrial parks, hospitals, hotels, churches, etc. The market share of Injera is not limited only to the town rather it can be expanded to the abroad market. On the other hand, the Ethiopian airlines port under construction nearby Nekemte town brings another opportunity to reach the abroad demand for Injera consumption.

The other major economic opportunities of women engaged on trading Injera is the existence of high willingness to take entrepreneurship related training that may improve their awareness and skills. All women $(50 ; 100 \%)$ currently engaged on Injera trading and included in this study have full willingness to take entrepreneurship related training in order to fill the existing knowledge gap and improve their future 
plan and living standard. They have also an interest to take food preparation related training to advance their indigenous knowledge and skills of Injera preparation.

\section{Conclusions And Recommendation}

In line with the study aims, the study results confirm the existence of different social and economic opportunities for women selling Injera on street at Nekemte town. The major social opportunities of women engaged on selling Injera on the street at Nekemte town were the existence of interest to continue in the engagement; having indigenous knowledge and skills; and existence of full interest to work in cooperative. The mentionable economic opportunities for the women were existence of adequate and cheap utility facilities; availability of necessary cereal grains; existence of high demand for Injera consumption and high willingness to take training on entrepreneurship and food preparation. It is recommended to empower women engaged on selling Injera on the street at Nekemte town by modernizing and enterprising the Injera product through developing scientific and community based project.

\section{Declarations}

\section{Acknowledgements}

Not applicable.

\section{Authors' contributions}

TTE carried out all activities related to the study and manuscript preparation from the beginning to end.

\section{Funding}

No fund received for this research.

\section{Availability of data and materials}

Primary data is available that collected via questionnaire.

\section{Competing interests}

The author declares no competing interests.

\section{Author details}


Wollega university, Department of Accounting and Finance, Assistant Professor of Finance.

\section{References}

1. Addis, A., \& Fetien, A. (2017). Effect of Different Cereal Blends on the Quality of Injeraa Staple Food in the Highlands of Ethiopia. Momona Ethiopian Journal of Science (MEJS), 9(2), 232-241.

2. Alemayehu, A., Meskerem, M., \& Hailay, G. (2016). Injera Preparation from Taro (Colocasiaesculenta) and Teff (Eragrostistef). Flour.International Journal of Sciences: Basic and Applied Research (IJSBAR., 30(1), 196-204.

3. Dijkstra, A., Polman, J., van Wulfften-Palthe, A., Gamboa, P. A., \& van Ekris, L. (2008). Survey on the nutritional and health aspects of teff (Eragrostistef).Avalable at: https://www.docdeveloppementdurable.org/file/Culture-plantesalimentaires/FICHES_PLANTES/teff/Survey\%20o n\%20the\%20nutritional\%20and\%20health\%20asp ects\%20of\%20teff.pdf.

4. Ghebrehiwot, H. M., Shimelis, H. A., Kirkman, K. P., Laing, M. D., \& Mabhaudhi, T. (2016). Nutritional and Sensory Evaluation of Injera Prepared from tef and Eragrostiscurvula (Schrad.)Nees.Flours with Sorghum Blends. Frontiers in Plant Science, 7, 1059. doi:10.3389/fpls.2016.01059.

5. Yimer, M. (2009). The Mineral Content and Sensory Properties of Injera Made from the Faba Bean, Sorghum and Tef Flour Blend. International Journal Of Nutrition, 4(2), 1-13.

6. Yoseph, L. A., Shimelis, A. E., Workineh, A., Villanueva, M., \& Ronda, F. (2018). The effect of mechanical kneading and absit preparation on tefinjera quality. African Journal of Food Science, 12(10), 246-253.

\section{Figures}




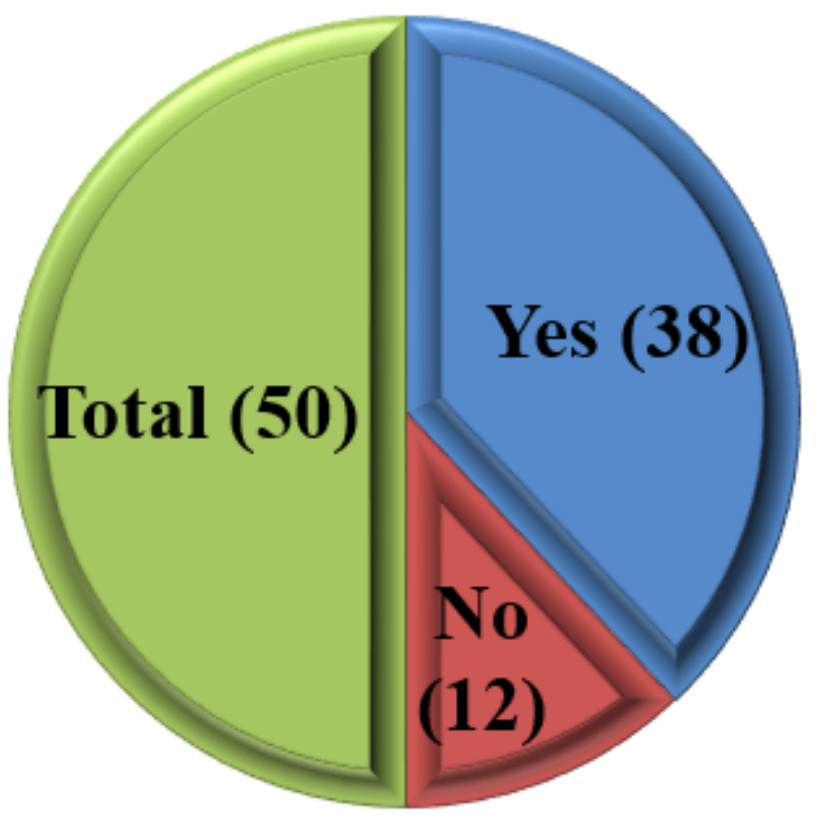

- Yes

四o

Total

Figure 1

Interest to Continue with the career

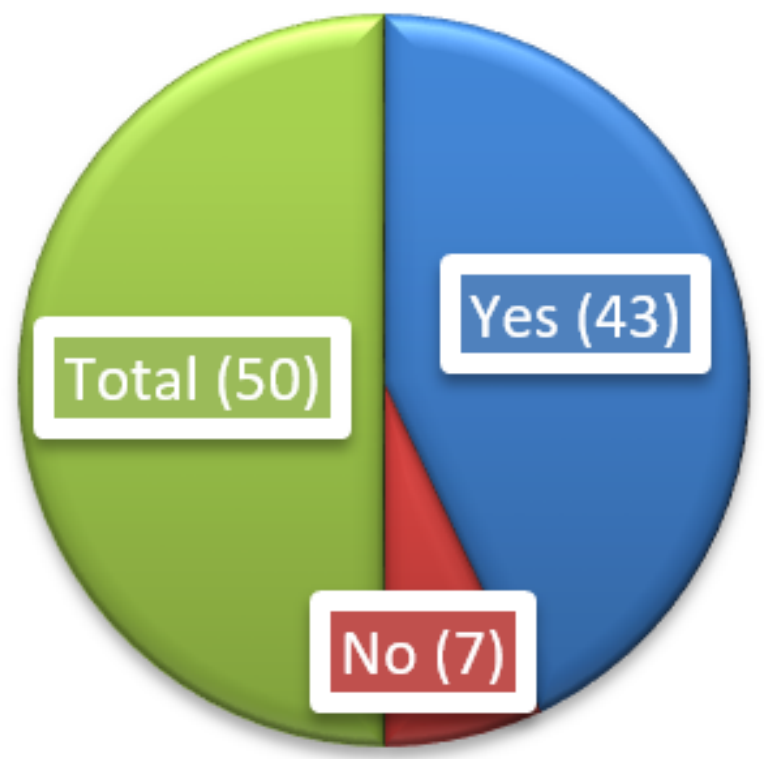

$\nabla$ Yes

$\square$ No

$\square$ Total

Figure 2

Interest to work in cooperative 